\title{
O POTENCIAL DE GERAÇÃO DE BIOGÁS PROVENIENTE DA CRIAÇÃO DE SUÍNOS NO OESTE DO PARANÁ: UM ESTUDO EXPLORATÓRIO
}

\author{
Udo Strassburg* \\ Nilton Marques de Oliveira** \\ Weimar Freire da Rocha Junior ${ }^{* * *}$
}

RESUMO: Este trabalho teve o objetivo de verificar o potencial e a perspectiva da produção de biogás no Oeste do Paraná. Utilizou-se de uma metodologia exploratória com base na literatura. Para tanto, o referencial teórico foi centralizado na geração de biogás na atividade suína, sua produção, sua perspectiva e seu potencial de produção de biogás e as formas de utilização. Os dados utilizados e trabalhados foram obtidos junto ao IPEADATA, à EMBRAPA e à Abipecs. Os resultados apontaram que o Oeste do Paraná tem um grande potencial para geração de biogás, tendo, em 2012, uma população de suínos de 2.085.267 cabeças, com a capacidade de geração de dejetos de $12.094 .548 \mathrm{~kg}$. Com essa matéria-prima há condições de gerar $4.233 .092 \mathrm{~m}^{3}$ de biogás. As perspectivas dos agentes da atividade suína estarem se envolvendo, cuidando do meio ambiente e, consequentemente, produzindo biogás, são grandes, pois os resultados se mostram favoráveis para que isso aconteça. Assim, o que é necessário para a expansão da produção do biogás são estímulos do governo no sentido de regulamentar a atividade e oferecer incentivos para a produção de energia renovável.

PALAVRAS-CHAVE: Atividade suína; Cuidado com o meio ambiente; Geração de biogás.

\section{THE CAPACITY OF BIOGAS PRODUCTION IN SWINE BREEDING IN WESTERN PARANÁ: AN EXPLORATORY STUDY}

ABSTRACT: The potentiality and perspectives for the production of biogas in western Paraná, Brazil, are analyzed through an exploratory methodology based on specialized

\footnotetext{
Doutor em Desenvolvimento Regional e Agronegócio - PGDRA (UNIOESTE), Toledo (PR), Brasil.

E-mail: udo.strassburg@unioeste.br

** Doutor em Desenvolvimento Regional e Agronegócio - PGDRA (UNIOESTE) Toledo (PR), Brasil; Docente do Programa de Pós-graduação Desenvolvimento Regional - PGDR (UFT), Palmas (TO), Brasil.

*** Doutor em Engenharia de Produção, Universidade Federal de Santa Catarina (UFSC); Docente no Programa de Pós-graduação em Desenvolvimento Regional e Agronegócio - PPGDRA (Mestrado e Doutorado) e curso graduação em Ciências Econômicas (UNIOESTE), Campus Toledo (PR), Brasil.
} 
literature. The theoretical referential focused on the production of biogas in swine breeding, production, perspectives and potential in producing biogas and its use. Data were retrieved from IPEADATA, EMBRAPA and Abipecs. Results demonstrate that the western region of the state of Paraná, Brazil, has great possibilities in biogas production due to swine herd which amounted to 2.085.267 units in 2012, with the capacity of producing $12.094 .548 \mathrm{~kg}$ in waste products, capable of producing $4.233 .092 \mathrm{~m}^{3}$ of biogas. The perspectives of agents involved in swine breeding, while taking care of the environment and producing biogas, are very high since results are favorable. However, biogas expansion requires government funds to regulate the activity and supply incentives for the production of renewable energy.

KEY WORDS: Swine-breeding; Production of biogas; Caring for the environment.

\section{INTRODUÇÃO}

O consumo de energia cresce a cada dia, seja pelas atividades que hoje são dependentes de energia, seja pela busca do conforto e comodidade. E é por causa desse consumo desenfreado que buscam-se novas alternativas energéticas para o mundo, visto que as maiores fontes de matéria-prima para a produção de energia são finitas, não renováveis, como o petróleo e o carvão, por exemplo, que causam grandes prejuízos ao meio ambiente, gerando gases de efeito estufa.

Segundo Bley Jr. (2014), os três principais eixos da sobrevivência humana estão relacionados à água, aos alimentos e à energia. Sobre a água e alimentos, é incontestável a relação de necessidade para os seres humanos. A energia, por sua vez, está relacionada à qualidade de vida que os humanos desejam, significando que, a cada dia, são criadas outras necessidades, que podem ser classificadas como secundárias, elevando tais níveis e, consequentemente, o consumo de energia.

De acordo com Goldenberg (2000, p. 91), "O consumo de energia no mundo cresce cerca de $2 \%$ ao ano e deverá dobrar em 30 anos se prosseguirem as tendências atuais". Além disso, segundo o autor, "cerca de 85\% do enxofre lançado na atmosfera (principal responsável pela poluição urbana e pela chuva ácida) origina-se na queima de carvão e petróleo, bem como 75\% das emissões de carbono".

Partindo dessas informações, pode-se dizer que a energia é um item 
essencial para o desenvolvimento humano, e isso tem provocado preocupações às instituições e às organizações no mundo inteiro. O direcionamento que está sendo dado a esse problema é a busca por novas tecnologias para melhorar a eficiência na utilização dos combustíveis fósseis, com maior eficácia para sua utilização. Com isso haverá a prolongação da vida útil das reservas, a descoberta e o desenvolvimento de fontes alternativas de energia, que sejam sustentáveis. Com essas atitudes, os países aumentarão a participação no consumo de fontes renováveis de energia, como, por exemplo, a utilização da energia dos ventos, da biomassa (etanol, biogás, biodiesel etc.) e da luz solar.

No caso específico do biogás, existe a possibilidade de transformar dejetos em fonte de energia com múltiplas funções, a saber: crédito de carbono, cogeração de energia, geração de energia para automóveis, para residências e indústrias, com a possibilidade de todas elas serem utilizadas em conjunto. A tendência da produção de biogás no mundo é de crescer principalmente pelo aumento da demanda e pelo fato de se tratar de uma energia que pode ser produzida via Mecanismos de Desenvolvimento Limpo (MDL).

No Oeste do Paraná estão situados grandes produtores de aves e suínos, como também frigoríficos de abate para a comercialização. Por outro lado, a produção de dejetos também é muito grande, os quais podem se transformar em potencial de geração de energia limpa. Esses dejetos, se despejados no meio ambiente, podem causar um grande problema para a natureza, principalmente nos rios e lagos, causando muitos prejuízos, causando a contaminação do lençol freático, mortandade de peixes, poluições de rios e lagos, com a eutrofização dos corpos de água.

Diante desse breve panorama, o objetivo do presente trabalho foi verificar o potencial e a perspectiva da produção de biogás no Oeste do Paraná. Essa é uma produção de energia alternativa, renovável e limpa; além disso, é necessária, pois os seres humanos são vorazes consumidores de energia, consomem muito mais energia do que necessitam para sobreviver, quer seja para uma simples necessidade básica, quer para colocar em funcionamento algum equipamento para o seu conforto.

Isso posto, este artigo está divido em quatro partes, a saber: a primeira é composta da introdução e do desenvolvimento; a segunda é composta da descrição 
do material e dos métodos utilizados na pesquisa; a terceira parte apresenta os resultados e discussões; e, por fim, na quarta parte encontram-se as considerações finais.

\section{DESENVOLVIMENTO}

\subsection{O BIOGÁS DA ATIVIDADE SUÍNA NO OESTE PARANAENSE}

O Brasil está sendo considerado como um país com potencial na produção de energias renováveis a partir da biomassa, principalmente por sua diversidade de produção e de seu tamanho. Para o presente, o destaque é a biomassa proveniente da atividade suína. Para incentivar a produção do biogás, proteger o meio ambiente e gerar riquezas para o país, foi organizado no Oeste do Paraná o Centro de Estudos do Biogás para o desenvolvimento de pesquisas científicas e experimentos que, posteriormente, serão transformados em tecnologias que possam ser utilizadas por toda a cadeia de suprimentos do biogás do Brasil.

Esse Centro foi formado por meio de convênios firmados entre a Secretaria da Ciência, Tecnologia e Ensino Superior, Governo do Paraná e Itaipu Binacional, e está sendo gerido pelo Parque Tecnológico Itaipú - PTI. O Centro está aplicando seus estudos em diversas unidades produtoras de suínos, em diversas cidades do Oeste paranaense, entre elas: Marechal Cândido Rondon, São Miguel do Iguaçu, Itaipulândia, Matelândia, Vera Cruz do Oeste e Foz do Iguaçu.

A abrangência dos estudos e a amplitude geográfica do Centro estão representadas

por meio das Unidades de Demonstração, do Laboratório de Biogás, do Núcleo de Capacitação e do Observatório de Energias Renováveis para a América Latina e o Caribe. A Plataforma Itaipú de Energias Renováveis mantém projetos de desenvolvimento sustentável, com foco nas metas globais de redução de gases de efeito estufa e no biogás como produto vetor da transformação social (ITAIPU BINACIONAL, 2011).

Dentre as metodologias desenvolvidas pode-se destacar a "Geração 
distribuída de Energia Elétrica", que consiste em conectar pequenos geradores de energia (abaixo de 1MW) na rede de distribuição. Desenvolveu-se, também, pequenos gasômetros para o armazenamento do biogás a serem utilizados em condomínios. Além disso, foram desenvolvidos o painel de comando e sincronização de energia elétrica gerada com a rede de distribuição, além de um sistema de medição para monitoramento da operação dos biodigestores, de gasoduto e de unidades de produção (ITAIPU BINACIONAL, 2011).

O Centro de Estudos do Biogás, em Foz do Iguaçu, nas dependências do Parque Tecnológico de Itaipu, está trabalhando no sentido de pesquisar, de desenvolver tecnologias e metodologias, de conscientizar e de firmar convênios com associações, condomínios e produtores rurais que queiram aplicar e trabalhar com os resultados desenvolvidos por eles.

O biogás é proveniente do tratamento dado aos resíduos que, na maioria das vezes, não têm cheiro agradável, juntam moscas e, se jogados no meio ambiente, são grandes poluidores e emitem gases que agravam o efeito estufa. Esses resíduos, que anteriormente eram jogados no meio ambiente, muitas vezes lançados nos rios, afetavam uma bacia hidrográfica inteira ou eram despejados em grandes valas a céu aberto, emitindo os gases prejudiciais à natureza, com risco de infiltração no solo. Todavia, agora esses resíduos podem ser aproveitados como matéria-prima para a geração de outros produtos, com valor agregado. Tais produtos possuem valor de mercado e podem ser utilizados para a diminuição dos custos das propriedades e ganhos adicionais com a venda dos mesmos (PERDOMO et al., 1999).

Para a produção de biogás, além da utilização dos dejetos de animais (bovinos, equinos, suínos, caprinos e aves), ele pode ser gerado com a utilização dos dejetos provenientes do esgoto urbano, que é acumulado nas estações de tratamento de esgoto, e dos dejetos provenientes do lixo urbano, acumulados em aterros sanitários que, após um processo de retirada de materiais recicláveis, também passa a ser útil na geração de energia (WILLER et al., 2010).

Nesse sentido, Santos (2009) destaca que o biogás é proveniente da degradação química de organismos mortos ou de excreções, por meio da ação de microorganismos decompositores anaeróbicos que catalisam as reações geradoras do mesmo. 
O biogás tem um poder energético significativo, como se pode verificar na comparação com outros produtos geradores de energia. Conforme Santos (2009), um metro cúbico $\left(1 \mathrm{~m}^{3}\right)$ de biogás equivale energeticamente a $1,5 \mathrm{~m}^{3}$ de gás de cozinha; 0,52 a 0,6 litros de gasolina; $2,7 \mathrm{~kg}$ de lenha; 0,9 litros de álcool; $1,43 \mathrm{kWh}$ de eletricidade.

Além de o biogás ser um produto compatível com os produtos mais utilizados para a geração de energia, é um produto que é gerado por intermédio da retirada de resíduos do meio ambiente, os quais são altamente poluentes, tanto para o ar quanto para a água e o solo (ZANELLA, 2012).

Como resultado final do processo de tratamento dos resíduos provenientes das origens especificadas anteriormente, podem-se obter pelo menos três produtos distintos, que terão valor financeiro. Além do biogás, tem-se como produto final o biofertilizante e o crédito de carbono, pelo serviço de não deixar que gases poluentes sejam lançados na atmosfera (SANTOS; OLIVEIRA, 2011).

\subsection{O BIOFERTILIZANTE}

O biofertilizante é produzido após o processo de tratamento dos resíduos, junto aos biodigestores, onde é realizada a fermentação da matéria orgânica decomposta, chamada de digestão anaeróbica dos resíduos orgânicos. Esse ambiente é onde as bactérias anaeróbicas estão em condições favoráveis para a produção do biogás, ou seja, esse é um processo pelo qual os gases prejudiciais ao meio ambiente são extraídos da biomassa (dejetos), os quais ficam retidos em grandes balões para serem transportados para ambientes armazenadores, conduzidos por canos. Por causa da retirada dos gases prejudiciais ao meio ambiente, da biomassa (dejetos), é que o biofertilizante pode ser utilizado nas plantações e lavouras como forma de adubo, sem prejuízo ao meio ambiente (NASCIMENTO, 2010).

Conforme Nascimento (2010, p. 61)

o biofertilizante derivado dos biodigestores anaeróbios é um efluente líquido que, após a fermentação das bactérias no interior do equipamento, pode alterar beneficamente as propriedades físicas, químicas e biológicas do solo. Pode, ainda, melhorar a capacidade de retenção de água, por ser uma matéria orgânica, além de possuir macronutrientes como nitrogênio $(\mathrm{N})$, fósforo $(\mathrm{P})$ e potássio $(\mathrm{K})$. 
Esses macronutrientes são essenciais para o crescimento e para o desenvolvimento das plantas. Ao utilizarem o biofertilizante, os agricultores estarão agindo de forma ambientalmente correta e também economizando recursos ao deixar de comprar adubo mineral para ser utilizado nas plantações (NASCIMENTO, 2010).

\subsection{CRÉDITO DE CARBONO}

A discussão feita entre diversos países para se pensar a diminuissão da emissão de gases que causam o efeito estufa teve início com a ECO-92, que ocorreu no Rio de Janeiro, enfatizando a questão do "Desenvolvimento Sustentável". Essa discussão se consolidou com o Protocolo de Kyoto, firmado em 1997, quando alguns países de grande influência, como os EUA, ficaram de fora. Nesse acordo incluiu-se o conceito de Mecanismo de Desenvolvimento Limpo (MDL), que está relacionado à limitação e à redução de gases de efeito estufa. Para facilitar e incentivar esse esforço, instituiu-se uma moeda de troca que se chamou de "créditos de carbono" (SANTOS; OLIVEIRA, 2011).

Créditos de Carbono correspondem às autorizações, na forma de certificado, adquiridas de diversos países que conseguiram baixar os níveis de emissão de gases poluentes, os quais dão direito de poluir ao adquirente. Em outras palavras, os países que não conseguem diminuir os danos causados ao meio ambiente pagam a outros para que tenham maiores condições de contabilizar a diminuição da emissão de gases de efeito estufa ou aumentar a captura de gás carbônico que iria ser lançado na atmosfera. Os países em desenvolviento são os prioritários na "produção" dos créditos e os desenvolvidos os compradores destes créditos (SANTOS; OLIVEIRA, 2011).

Uma das metas firmadas no protocolo de Kyoto foi a de diminuir a emissão de gases de efeito estufa em 5\% entre 2008 e 2012. Em referência à comercialização, um crédito de carbono corresponde a uma tonelada de $\mathrm{CO}_{2}$, que foi deixado de ser jogado no meio ambiente e pode ser vendido por US\$ 5,66 a tonelada. No Brasil, os créditos de carbono movimentam cerca de US\$ 400 milhões por ano, somando os investimentos para gerar esses créditos, o mercado movimenta aproximadamente US\$1,6 bilhão por ano (SANTOS; OLIVEIRA, 2011). 


\subsection{DESVANTAGENS EM RELAÇÃO AO TRATAMENTO DA BIOMASSA (DEJETOS)}

Os benefícios que o tratamento da biomassa proporciona a todos envolvem desde a questão ambiental até a questão de retorno financeiro, o que é muito bom, pois serve como nova fonte de renda para quem está envolvido. Não obstante, existem também algumas desvantagens com a depreciação acelerada de alguns bens, pelo poder corrosivo dos gases e o cuidado com o manuseio com os produtos resultantes das combinações, com o tratamento da biomassa (ZANELLA, 2012).

Andersson et al. (2004) destacam que a junção da concentração de sulfeto de hidrogênio e amoníaco se transforma em um agente corrosivo para diversos materiais como cobre, latão e aço, e esses podem se tornar tóxicos, dependendo das condições e do tipo de ação e manuseio com os mesmos.

\section{MATERIAIS E MÉTODOS}

A metodologia utilizada para realizar o presente trabalho está voltada para uma pesquisa exploratória, com base na literatura disponível mediante a leitura de livros e revistas. Também foi apurada a taxa de crescimento da produção de suínos, projeção de biogás a ser gerado e a transformação em produto de nosso cotidiano, tomando por base os dados do IPEADATA, EMBRAPA, Abipecs.

Para a produção de biogás, a matéria-prima a ser utilizada refere-se aos dejetos de suínos. Estão inclusos nessa composição os excrementos, a urina e a água utilizada para a limpeza dos chiqueirões. Conforme dados de Oliveira (1993), a média de produção de excrementos e urina, em $\mathrm{Kg} / \mathrm{dia}$, que um suíno produz é de $5,80 \mathrm{Kg}$. Em relação à capacidade de produção de biogás que pode ser obtida com a biomassa, oriunda da criação de suínos, medida $\mathrm{em}^{3}$ de biogás por $\mathrm{Kg}$ de material orgânico é de 0,35 m³ (NOGUEIRA, 1986). 


\section{RESULTADOS E DISCUSSÕES}

A atividade suinocultora está em crescimento no Brasil e poderá ser responsável pela geração de parte da energia alternativa que tanto o país necessita para atender à crescente demanda, ocasionada pelo crescimento da economia.

Conforme dados da Embrapa, a produção brasileira de suínos apresenta-se da seguinte forma (Tabela 1$)$ :

Tabela 1. Produção Brasileira de Suínos de 2004-2012 (mil cabeças)

\begin{tabular}{lccccccccc}
\hline \multicolumn{1}{c}{ Tipos/Anos } & $\mathbf{2 0 0 4}$ & $\mathbf{2 0 0 5}$ & $\mathbf{2 0 0 6}$ & $\mathbf{2 0 0 7}$ & $\mathbf{2 0 0 8}$ & $\mathbf{2 0 0 9}$ & $\mathbf{2 0 1 0}$ & $\mathbf{2 0 1 1}$ & $\mathbf{2 0 1 2}$ \\
\hline Total Ind. & 26.550 & 28.030 & 30.724 & 31.806 & 32.693 & 34.687 & 35.101 & 36.469 & 37.631 \\
Subsistência & 6.759 & 5.921 & 5.816 & 5.036 & 5.045 & 4.694 & 4.152 & 3.789 & 3.696 \\
\hline Brasil & $\mathbf{3 3 . 3 0 9}$ & $\mathbf{3 3 . 9 5 1}$ & $\mathbf{3 6 . 5 4 0}$ & $\mathbf{3 6 . 8 4 2}$ & $\mathbf{3 7 . 7 3 8}$ & $\mathbf{3 9 . 3 8 1}$ & $\mathbf{3 9 . 2 5 3}$ & $\mathbf{4 0 . 2 5 8}$ & $\mathbf{4 1 . 3 2 7}$ \\
\hline Santa Catarina & 7.071 & 7.458 & 8.421 & 8.670 & 8.422 & 8.640 & 8.580 & 8.989 & 9.153 \\
Rio G. do Sul & 4.791 & 5.242 & 5.609 & 5.800 & 6.366 & 7.059 & 6.895 & 7.000 & 7.050 \\
Paraná & 4.587 & 4.781 & 5.009 & 5.084 & 5.166 & 5.673 & 5.710 & 5.923 & 6.020 \\
\hline Sul do Brasil & $\mathbf{1 6 . 4 4 9}$ & $\mathbf{1 7 . 4 8 1}$ & $\mathbf{1 9 . 0 3 9}$ & $\mathbf{1 9 . 5 5 4}$ & $\mathbf{1 9 . 9 5 4}$ & $\mathbf{2 1 . 3 7 2}$ & $\mathbf{2 1 . 1 8 5}$ & $\mathbf{2 1 . 9 1 2}$ & $\mathbf{2 2 . 2 2 3}$ \\
\hline Tx & & & & & & & & & \\
Crescimento & - & $4,23 \%$ & $4,77 \%$ & $1,50 \%$ & $1,61 \%$ & $9,81 \%$ & $0,65 \%$ & $3,73 \%$ & $1,64 \%$ \\
PR & & & & & & & & & \\
\hline
\end{tabular}

Fonte: Abipecs (2012); Embrapa (2012).

O que se pode verificar é que a atividade, no Brasil e no Paraná, vem crescendo gradativamente, ano após ano. Dentre os Estados produtores de suínos no Brasil, o Paraná está classificado entre os três maiores. Outro dado interessante é que esses três Estados somavam, em 2012, 53,77\% da produção brasileira de suínos e 59,05\% da produção industrial, ou seja, sem contar com a criação para subsistência, correspondendo a mais da metade das cabeças criadas e abatidas no Brasil (EMBRAPA, 2012). 


\subsection{A PERSPECTIVA E POTENCIAL DO BIOGÁS NO OESTE PARANAENSE}

A perspectiva da produção do biogás no Estado do Paraná é crescente, assim como é crescente a produção de suínos. Na Tabela 2 está exposta a produção de suínos no Paraná e desmembrada para a Meso e Microrregião Oeste, em que é possível visualizar esse crescimento gradativo, conforme dados do IPEADATA (2012).

Tabela 2. Produção de Suínos na região Oeste do Paraná (cabeças)

\begin{tabular}{|c|c|c|c|c|c|c|c|c|c|}
\hline Paraná & 2004 & 2005 & 2006 & 2007 & 2008 & 2009 & 2010 & 2011 & 2012 \\
\hline Paraná & 4.587 .000 & 4.781 .000 & 5.009 .000 & 5.084 .000 & 5.166 .000 & 5.673 .000 & 5.710 .000 & 5.923 .000 & 6.020 .000 \\
\hline $\begin{array}{l}\text { Tx Crescimento } \\
\text { PR }\end{array}$ & - & $4,23 \%$ & $4,77 \%$ & $1,50 \%$ & $1,61 \%$ & $9,81 \%$ & $0,65 \%$ & $3,73 \%$ & $1,64 \%$ \\
\hline Microrregião & 2004 & 2005 & 2006 & 2007 & 2008 & 2009 & 2010 & 2011 & 2012 \\
\hline Toledo & 915.811 & 919.663 & 947.642 & 1.100 .543 & 1.118.294 & 1.228 .045 & 1.236 .054 & 1.282 .163 & 1.303 .161 \\
\hline Cascavel & 305.559 & 331.161 & 328.334 & 374.943 & 380.990 & 418.382 & 421.110 & 436.819 & 443.973 \\
\hline Foz do Iguaçu & 183.750 & 188.533 & 189.728 & 285.560 & 290.166 & 318.643 & 320.721 & 332.685 & 338.134 \\
\hline Mesorregião & 2004 & 2005 & 2006 & 2007 & 2008 & 2009 & 2010 & 2011 & 2012 \\
\hline $\begin{array}{l}\text { Oeste } \\
\text { Paranaense }\end{array}$ & 1.405 .120 & 1.439 .357 & 1.465 .704 & 1.761 .046 & 1.789 .450 & 1.965 .070 & 1.977 .886 & 2.051 .667 & 2.085 .267 \\
\hline
\end{tabular}

Fonte: IPEADATA (2012).

Verifica-se que quanto mais animais forem produzidos, mais dejetos serão acumulados, sendo necessário que toda a produção de dejetos seja utilizada para a produção de biogás. Nesse sentido, elaborou-se uma projeção de produção de biogás, biofertilizante e crédito de carbono, tanto para todo o Estado como desmembrando para a Meso e Microrregião Oeste.

No Quadro 1 estão as especificações utilizadas para a realização do cálculo da projeção. 
Quadro 1. Dados médios de dejetos e biogás por cabeça/dia

\begin{tabular}{|c|c|c|c|c|}
\hline Dejetos & Biogás & Cálculo & Bioferilizante & $\begin{array}{c}\text { Crédito de } \\
\text { Carbono }\end{array}$ \\
\hline$(1)$ & $(2)$ & $(1 \times 2)$ & $(=1)$ & $(3)$ \\
\hline Oliveira (1993) & Nogueira (1986) & Oliveira (1993) & $\begin{array}{l}\text { Santos e Oliveira } \\
(2011)\end{array}$ \\
\hline $\begin{array}{l}\text { Média de dejetos } \\
+ \text { urina por } \\
\text { cabeça/dia }\end{array}$ & $\begin{array}{l}\text { Rendimento de } \\
\text { Biogás por Kg } \\
\text { de dejetos + } \\
\text { urina }\end{array}$ & $\begin{array}{l}\text { Média de } \\
\text { produção de } \\
\text { Biogás por } \\
\text { cabeça/dia }\end{array}$ & $\begin{array}{l}\text { Média de dejetos } \\
+ \text { urina por } \\
\text { cabeça/dia }\end{array}$ & $\begin{array}{l}\text { Valor da } \\
\text { tonelada de CO2 } \\
\text { que não foi para } \\
\text { a atmosfera }\end{array}$ \\
\hline $5,80 \mathrm{~kg}$ & $0,35 \mathrm{~m}^{3}$ & $2,03 \mathrm{~m}^{3}$ & $5,80 \mathrm{~kg}$ & US\$ 5,60 \\
\hline
\end{tabular}

Fonte: Nogueira (1986); Oliveira (1993); Santos e Oliveira (2011).

$(*)$ A média foi calculada com base nos resultados de Nogueira (1986) e Oliveira (1993).

Para o cálculo do potencial de créditos de carbono que as regióes pesquisadas possuem, foi necessário utilizar uma metodologia descrita por Santos e Oliveira (2011), que serviu para o cálculo e transformação de $\mathrm{m}^{3} \mathrm{em}$ tonelada; para tanto, utilizou-se a fórmula (1) a seguir:

$$
D=M / V
$$

Onde: $\quad \mathrm{D}=$ Densidade Padrão para gás $\left(0,717 \mathrm{~kg} / \mathrm{m}^{3}\right)$;

$$
\begin{aligned}
& \mathrm{M}=\text { Massa }\left(\mathrm{kg} \mathrm{CO}_{2} \mathrm{~L}, \mathrm{~km}, \mathrm{~kg}^{\circ} \text { ou m} \mathrm{m}^{3}\right) ; \mathrm{e} \\
& \mathrm{V}=\text { Volume }\left(\mathrm{L}, \mathrm{km}, \mathrm{kg} \text { ou } \mathrm{m}^{3}\right) .
\end{aligned}
$$

Na Tabela 3, elaborada com dados do IPEADATA (2012), Oliveira (1993), Nogueira (1986) e Santos e Oliveira (2011), apresenta-se a projeção da geração dos produtos citados e o potencial paranaense, da Meso e da Microrregião Oeste. 
Tabela 3. Projeção da geração de biogás, biofertilizante e crédito de carbono

\begin{tabular}{|c|c|c|c|c|c|c|c|c|}
\hline & & 1 & 2 & 3 & 4 & 5 & 6 & 7 \\
\hline Lo & & $\begin{array}{c}\mathbf{n}^{\mathbf{o}} \\
\text { Cabeças } \\
2012\end{array}$ & $\begin{array}{c}\text { Média } \\
\text { Biogás } \\
\text { cabeça/ } \\
\text { dia }\left(\mathbf{m}^{3}\right)\end{array}$ & $\begin{array}{c}\text { Biogás } \\
\text { Gerado } \\
\left(\mathrm{m}^{3}\right)\end{array}$ & $\begin{array}{c}\text { Biofertilizante } \\
\text { gerado } \\
(5,8 \mathrm{~kg})\end{array}$ & $\begin{array}{c}\text { Transf. } \\
\text { de } \mathbf{m}^{3} \\
\text { em } \\
\text { Tonelada }\end{array}$ & $\begin{array}{c}\text { Crédito } \\
\text { de } \\
\text { Carbono } \\
\text { (US\$ } \\
\mathbf{5 , 6 0 )}\end{array}$ & $\begin{array}{c}\text { Crédito } \\
\text { de } \\
\text { Carbono } \\
\text { R\$ } \\
02 / 2014 \text { ) }\end{array}$ \\
\hline & & 1 & 2 & $(1 \times 2)$ & $(1 \times 5,8)$ & $\begin{array}{l}(d= \\
m / v)\end{array}$ & $(5 \times 5,60)$ & $(6 \times 2,38)$ \\
\hline Par & & 6.020 .000 & 2,03 & 12.220 .600 & 34.916 .000 & 8.762 & 49.068 & 116.782 \\
\hline & $\begin{array}{l}\text { rregião } \\
e^{-1}\end{array}$ & 2.085 .267 & 2,03 & 4.233 .092 & 12.094 .549 & 3.035 & 16.997 & 40.452 \\
\hline & Toledo & 1.303 .161 & 2,03 & 2.645 .417 & 7.558 .334 & 1.897 & 10.622 & 25.280 \\
\hline 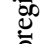 & Cascavel & 443.973 & 2,03 & 901.265 & 2.575 .043 & 646 & 3.619 & 8.613 \\
\hline $\bar{\Sigma}$ & $\begin{array}{l}\text { Foz do } \\
\text { Iguaçu }\end{array}$ & 338.134 & 2,03 & 686.412 & 1.961 .177 & 492 & 2.756 & 6.559 \\
\hline
\end{tabular}

Fonte: Adaptado de Nogueira (1986); Oliveira (1993); Santos e Oliveira (2011); IPEADATA (2012).

Em 2012, o Paraná teve a possibilidade de produzir $12.220 .600 \mathrm{~m}^{3}$ de biogás, a Mesorregião Oeste com o potencial de produzir 34,64\% do total (Tabela 3). Levando-se em consideração que o Paraná é composto por 10 mesorregiões, o potencial de produção de biogás proveniente da atividade suína no Oeste do Paraná é significativo. No tocante a esse potencial, analisado nas três microrregiões do Oeste, o de Toledo seria responsável por $62,49 \%$, o de Cascavel seria responsável por 21,29\% e o de Foz do Iguaçu por 16,22\% da produção de biogás.

A Tabela 4 mostra o equivalente do biogás em produtos mais comuns de nosso cotidiano: 
Tabela 4. Potencial de biogás equivalente em produtos de nosso cotidiano

\begin{tabular}{|c|c|c|c|c|c|c|c|}
\hline \multicolumn{2}{|c|}{ Locais } & $\begin{array}{c}\text { Biogás } \\
\text { Gerado } \\
\left(\mathrm{m}^{3}\right)\end{array}$ & $\begin{array}{l}\text { Gás de } \\
\text { cozinha }\end{array}$ & Gasolina & Lenha & Alcool & $\begin{array}{c}\text { KWh de } \\
\text { Eletricidade }\end{array}$ \\
\hline \multicolumn{2}{|c|}{$\begin{array}{llll}\begin{array}{l}\text { Equivalente a } \\
\text { biogás }\end{array} & \mathbf{m}^{3} \\
\text { biog } & & \end{array}$} & $1 \mathrm{~m}^{3}$ & $1,5 \mathrm{~m}^{3}$ & $0,56 \mathrm{~L}$ & $2,7 \mathrm{~kg}$ & 0,9L & $1,43 \mathrm{Kwh}$ \\
\hline \multicolumn{2}{|c|}{ Paraná } & 12.220 .600 & 18.330 .900 & 6.843 .536 & 32.995 .620 & 10.998 .540 & 17.475 .458 \\
\hline \multicolumn{2}{|c|}{ Mesorregião Oeste } & 4.233 .092 & 6.349 .638 & 2.370 .532 & 11.429 .348 & 3.809 .783 & 6.053 .322 \\
\hline \multirow{3}{*}{ 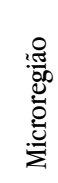 } & Toledo & 2.645 .417 & 3.968 .125 & 1.481 .433 & 7.142 .625 & 2.380 .875 & 3.782 .946 \\
\hline & Cascavel & 901.265 & 1.351 .898 & 504.709 & 2.433 .416 & 811.139 & 1.288 .809 \\
\hline & Foz do Iguaçu & 686.412 & 1.029 .618 & 384.391 & 1.853 .312 & 617.771 & 981.569 \\
\hline
\end{tabular}

Fonte: IPEADATA (2012); Oliveira (1993); Nogueira (1986); Santos e Oliveira (2011); e dados da pesquisa.

Comparando o equivalente energético do biogás com a gasolina, álcool e kwh de energia elétrica, os valores seriam os seguintes (Tabela 5):

Tabela 5. Potencial do biogás equivalnte em gasolina, álcool e kwh

\begin{tabular}{|c|c|c|c|c|c|c|c|}
\hline \multirow{2}{*}{\multicolumn{2}{|c|}{$\begin{array}{l}\text { Locais } \\
\text { Produto do nosso } \\
\text { cotidiano }\end{array}$}} & \multicolumn{2}{|c|}{ Gasolina } & \multicolumn{2}{|c|}{ Alcool } & \multicolumn{2}{|c|}{ KWh de Eletricidade } \\
\hline & & $0,56 \mathrm{~L}$ & $\begin{array}{c}\mathrm{R} \$ 3,29 \\
\mathrm{p} / \mathrm{L}\end{array}$ & $0,9 \mathrm{~L}$ & $\begin{array}{c}\mathrm{R} \$ 2,10 \\
\mathrm{p} / \mathrm{L}\end{array}$ & $1,43 \mathrm{kwh}$ & $\begin{array}{l}\mathrm{R} \$ 0,49 \mathrm{p} / \\
\mathrm{kwh}\end{array}$ \\
\hline \multicolumn{2}{|c|}{ Paraná } & 6.846 .536 & 22.515 .233 & 10.998 .540 & 23.096 .934 & 17.475 .458 & 8.562 .974 \\
\hline \multicolumn{2}{|c|}{ Mesorregião Oeste } & 2.370 .532 & 7.799 .049 & 3.809 .783 & 8.000 .544 & 6.053 .322 & 2.966 .128 \\
\hline \multicolumn{2}{|c|}{$\begin{array}{l}\text { Produto do nosso } \\
\text { cotidiano }\end{array}$} & $0,56 \mathrm{~L}$ & $\begin{array}{c}\mathrm{R} \$ 3,29 \\
\mathrm{p} / \mathrm{L}\end{array}$ & $0,9 \mathrm{~L}$ & $\begin{array}{c}\mathrm{R} \$ 2,10 \\
\mathrm{p} / \mathrm{L}\end{array}$ & $1,43 \mathrm{kwh}$ & $\begin{array}{c}\mathrm{R} \$ 0,49 \mathrm{p} / \\
\mathrm{kwh}\end{array}$ \\
\hline \multirow{3}{*}{ 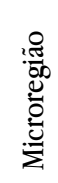 } & Toledo & 1.481 .433 & 4.873 .916 & 2.380 .875 & 4.999 .838 & 3.782 .946 & 1.853 .644 \\
\hline & Cascavel & 504.709 & 1.660 .491 & 811.139 & 1.703 .391 & 1.288 .809 & 631.517 \\
\hline & Foz do Iguaçu & 384.391 & 1.264 .646 & 617.771 & 1.297 .319 & 981.569 & 480.969 \\
\hline
\end{tabular}

Fonte: ANEEL (2015). 
$\mathrm{Na}$ Tabela 5, valores significativos mostram que a receita virá de algo que estava causando problemas aos produtores. Tais valores poderiam compor a diminuição dos custos das propriedades, configurando, assim, mais uma fonte de renda ao suinocultor. Outra forma de diminuir os custos da propriedade é com a utilização do biofertilizante. Nessa perspectiva, o Paraná terá o potencial de gerar aproximadamente 35.000 toneladas do produto, em que o produtor, além de economizar na compra de fertilizante, obterá ganho de produtividade na colheita. O crédito de carbono é o que trará menor retorno, mas não é o menos importante, pois se trata de um conjunto de procedimentos que serão realizados em benefício do meio ambiente e, em consequência disso, trará um ganho financeiro também.

\section{CONSIDERAÇÕES FINAIS}

Verificou-se que a criação de suínos no Oeste do Paraná tem produzido uma grande quantidade de dejetos. Essa situação está preocupando diversas entidades, as quais estão investindo em estudos e tecnologias no sentido de auxiliar e propor soluções para um dos maiores problemas dos produtores de suínos. Uma das soluções está no grande potencial para geração de biogás, tendo em 2012 uma população de suínos de 2.085.267 cabeças, com a capacidade de geração de dejetos de 12.094.548 Kg. Com essa matéria-prima há condições de gerar $4.233 .092 \mathrm{~m}^{3} \mathrm{de}$ biogás.

Com a quantidade de biogás equivalente em produtos do cotidiano das pessoas, o Paraná tem potencial correspondente a 6.843 .536 litros de gasolina, a 10.998.540 litros de álcool e/ou a $17.475 .458 \mathrm{kwh}$. Essa quantidade, multiplicada pelo valor de um litro de gasolina, um litro de álcool e $1 \mathrm{kwh}$, corresponderá a $\mathrm{R} \$$

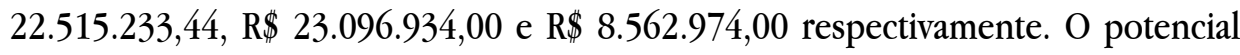
em relação ao Oeste do Paraná é de 2.370 .532 litros de gasolina, 3.809.783 litros de álcool e 6.053.322 kwh e os valores atuais correspondem a $\mathrm{R} \$ 7.799 .050,28, \mathrm{R} \$$ 8.000.544,00 e R \$ 2.966.128,00 respectivamente. São valores significativos, levando em consideração que esse montante veio de algo que estava causando transtornos aos produtores. 
As perspectivas dos produtores de suínos, ao cuidar do meio ambiente, ao mesmo tempo em que produzem biogás, são bastante interessantes pelo fato de que os incentivos gerados por Itaipu, por intermédio do Centro de Estudos do Biogás, se mostram favoráveis e economicamente viáveis. Outro fator importante é a organização dos produtores, que é feita por meio de sindicatos, de associações, de cooperativas, contibuindo para que possam se fortalecer e conseguir melhores resultados.

Sendo assim, para a expansão da produção do biogás, principalmente no Oeste do Paraná, serão necessários estímulos do governo no sentido de regulamentar adequadamente a atividade e oferecer incentivos para a produção de energia renovável, tão necessária para o mundo atual.

\section{REFERÊNCIAS}

ASSOCIAÇÃO BRASILEIRA DA INDÚSTRIA PRODUTORA E EXPORTADORA DE CARNE SUÍNA - ABIPECS. Disponível em: < http://www.abipecs.org.br/uploads/ relatorios/mercadointerno/producao/Producao2012.pdf > . Acesso em: 04 fev. 2014.

ANDERSSON, F. A. T.; KARLSSON, A.; SVENSSSON, B. H.; EJLERTSSON, J. Occurrence and abatement of volatile sulfur compounds during biogas production. Journal of the air \& waste management association, v. 54, n. 7, p. 855-861, 2004.

AGÊNCIA NACIONAL DE ENERGIA ELÉTRICA - ANEEL. Tarifas residenciais vigentes. Disponível em: <http://www.aneel.gov.br/area.cfm?idArea=493>. Acesso em: 08 jul. 2015.

BLEY JR., C. Biogás: a energia invisível. Foz do Iguaçu: Abril; Itaipu Binacional, 2014.

EMPRESA BRASILEIRA DE PESQUISA AGROPECUÁRIA - EMBRAPA. Suínos e Aves: dados estatísticos. Disponível em: <http://www.cnpsa.embrapa. br/?ids $=$ So6f90o4t $>$. Acesso em: 03 fev. 2014.

GOLDENBERG, J. Pesquisa e desenvolvimento na área de energia. São Paulo em Perspectiva, v. 14, n. 3, 2000.

INSTITUTO DE PESQUISA ECONÔMICA APLICADA - IPEADATA. Dados sobre a 
produção de suínos no Brasil. Disponível em: <www.ipeadata.gov.br > . Acesso em: 04 fev. 2014.

ITAIPU BINACIONAL. Cartilha: BIOGÁS o produto. [s.l.]: Itaupu Biancional, 2011.

NASCIMENTO, R. C. O uso do biofertilizante em solos agrícolas do cerrado da região do Alto Paranaíba (MG). Boletim Goiano de Geografia, v. 30, n. 2, p. 55-66, jul./ dez., 2010.

NOGUEIRA, L. A. Biodigestão: alternativa energética. São Paulo: Nobel, 1986.

OLIVEIRA, P. A. V. de. (Coord.). Manual de manejo e utilização dos dejetos de suínos. Concórdia: EMBRAPA-CNPSA, 1993.

PERDOMO, C. C.; COSTA, R. R. H. da.; MEDRI, W.; MIRANDA, C. R.; Dimensionamento de sistemas de tratamento (decantador de lagoas) e utilização de dejetos suínos. CT/234/Embrapa Suínos e Aves, p. 1-5, abr. 1999.

SANTOS, A. F. da S. Estudo de viabilidade da aplicação do Biogás no ambiente urbano. 2009. 16 f. Monografia (MBA em Administração e Organização) Universidade de São Paulo, FEA-USP, Ribeirão Preto, SP.

SANTOS, A. R. S. dos.; OLIVEIRA, R. C. Créditos de carbono: uma abordagem da mensuração contábil em empresas brasileiras. In: ENCONTRO LATINO AMERICANO DE INICIAÇÃO CIENTÍFICA; 13., 2011; ENCONTRO LATINO AMERICANO DE PÓSGRADUAÇÃ̃O, 9., 2011. Anais... [s.l.]: Universidade do Vale do Paraíba, 2011.

WILLER, E. M.; ALVES, L. R.; STADUTO, J. A. R.; GERMANN, C. Distribuição especial da cadeia agroindustrial de suínos no Oeste Paranaense. In: CONGRESSO DA SOBER, 48., 2010, Campo Grande. Anais... Campo Grande: Sober, 2010.

ZANELLA, M. G. Ambiente institucional e políticas públicas para o biogás proveniente da suinocultura. 2012. Dissertação (Mestrado em Bioenergia) Universidade Estadual do Oeste do Paraná, Toledo, PR.

Recebido em: 20 de março de 2015 Revisões em: 17 de agosto de 2015 Aceito em: 22 de dezembro de 2015 